"The effects of chaos edge management on intentional organizational forgetting with emphasis on quantum learning (case study: information technology-based organizations)"

AUTHORS Mehrdad Madhoushi

Azam Sazvar

Mehrdad Madhoushi and Azam Sazvar (2016). The effects of chaos edge management on intentional organizational forgetting with emphasis on quantum

ARTICLE INFO learning (case study: information technology-based organizations). Problems and Perspectives in Management, 14(3-si), 356-363. doi:10.21511/ppm.14(3si). 2016.08

DOI http://dx.doi.org/10.21511/ppm.14(3-si).2016.08

RELEASED ON Thursday, 15 September 2016

JOURNAL

"Problems and Perspectives in Management"

FOUNDER

LLC "Consulting Publishing Company "Business Perspectives"

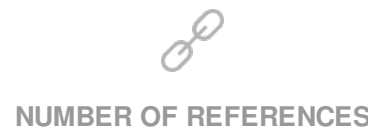

0
NUMBER OF FIGURES

0
NUMBER OF TABLES

0

(C) The author(s) 2022. This publication is an open access article. 
Mehrdad Madhoushi (Iran), Azam Sazvar (Iran)

\title{
The effects of chaos edge management on intentional organizational forgetting with emphasis on quantum learning (case study: information technology-based organizations)
}

\begin{abstract}
Unlike learning process, the critical phenomenon of organizational forgetting is not entirely understood. There are two categories of forgetting: accidental forgetting (not-preferred) and intentional forgetting (preferred). Therefore, all the variables that influence intentional forgetting can be important for organizational learning. One of them, which have been neglected thus far, is the edge of chaos in quantum learning. It is the point that a balance is achieved between stability and chaos. Organizational innovation, learning, and creativity all reach a proper level at this point. Along with emphasizing on these variables and surveying an IT-based organization, the present study is an attempt to discover the causal relationships between the variables. Based on the data from 289 filled out questionnaires, of which reliability and validity have been confirmed, structural equations model was developed in AMOS. The results showed that the all path coefficients were significant. In addition, comparison of goodness of fit indices and the standard range showed that all indices were acceptable and the main hypothesis regarding effectiveness of quantum learning on organizational forgetting was supported. The effect of quantum learning on organizational forgetting in non-standard and standard conditions was 0.51 and 0.28 , respectively.
\end{abstract}

Keywords: quantum learning, edge of chaos management, intentional organizational forgetting.

JEL Classification: D83, D23.

\section{Introduction}

There has been a transfer in the bases of competition among organizations from tangible/intangible sources to knowledge and information systems. Businesses that manage to preserve and utilize their knowledge enjoy better competitive advantages in the market.

Organizations have to face rapid and considerable changes in knowledge and skills requirement. To be more effective and survive, they need to abandon their old and unimportant knowledge and keep the necessary knowledge. However, learning is not all about accumulating knowledge and, in some cases, it entails abandoning unnecessary knowledge. The latter necessity is called organizational forgetting in the literature (Fernandez and Sune, 2009).

It is notable, however, that forgetting is not always desirable and in some cases means losing valuable knowledge. Therefore, organizational forgetting, like learning, needs programing and planning.

Clearly, learning and intentional forgetting do not take place in all organizational environments. Chaotic business environment and unpredictable environment, as far as learning and intentional forgetting is concerned, necessitates organizational structure, organizational leadership, and a decent environment for emergence of creativity and innovation. Creating such innovative environment needs attaining balance between stability, discipline, and homogeneity on one hand and chaos, disorder, and dispersion on the other

(C) Mehrdad Madhoushi, Azam Sazvar, 2016.

Mehrdad Madhoushi, Industrial Management Department, Faculty of Economics and administrative Science, University of Mazandaran, Iran. Azam Sazvar, Faculty of Economics \& Administrative Science, University of Mazandaran \& Nima Higher Education Institute, Iran. hand. This balance point is what we call the edge of chaos (Ozkan and Koseler, 2009)

In addition, quantum organization that supports quantum learning and development of the edge of chaos facilitates intentional organizational forgetting. Multi-aspect, multi-directional, crossover, relationbased, and hybrid organizations that undergo permanent change and unlimited adaptation are the places that quantum learning takes place (Malloch and Porter-O'Grady, 2007).

The present study surveys the effects of the aspects of quantum learning on intentional organizational forgetting in an IT-services organization affiliated with one of Iranian private banks. The company is a holding with several subsidiaries; however, only the managers and employees of the headquarters in two sites in Tehran were under study.

\section{Literature review}

1.1. Organizational forgetting. The concept of forgetting was introduced by Hedberg to highlight that organizational might intentionally forget their knowledge. He maintained that to remain in the progress path, organizations need to intentionally abandon their old and unnecessary knowledge; otherwise, risk extinction. They emphasized on intentional and unintentional aspects so that in the former case, the organization intentionally forgets current knowledge and in the latter case, forgetting in not intentional (Hedberg, 1981). The organization needs to preserve a knowledge, if it is useful for it and if it is not, before acquiring new knowledge, the old one must be removed (Aydin and Sahin Gormus, 2012). 
Azmi (2008) and DeHolan et al. (2004) classified different types of organizational forgetting (Fig. 1 and 2). Their classification is based on two aspects; type of forgotten knowledge (new or old knowledge) and

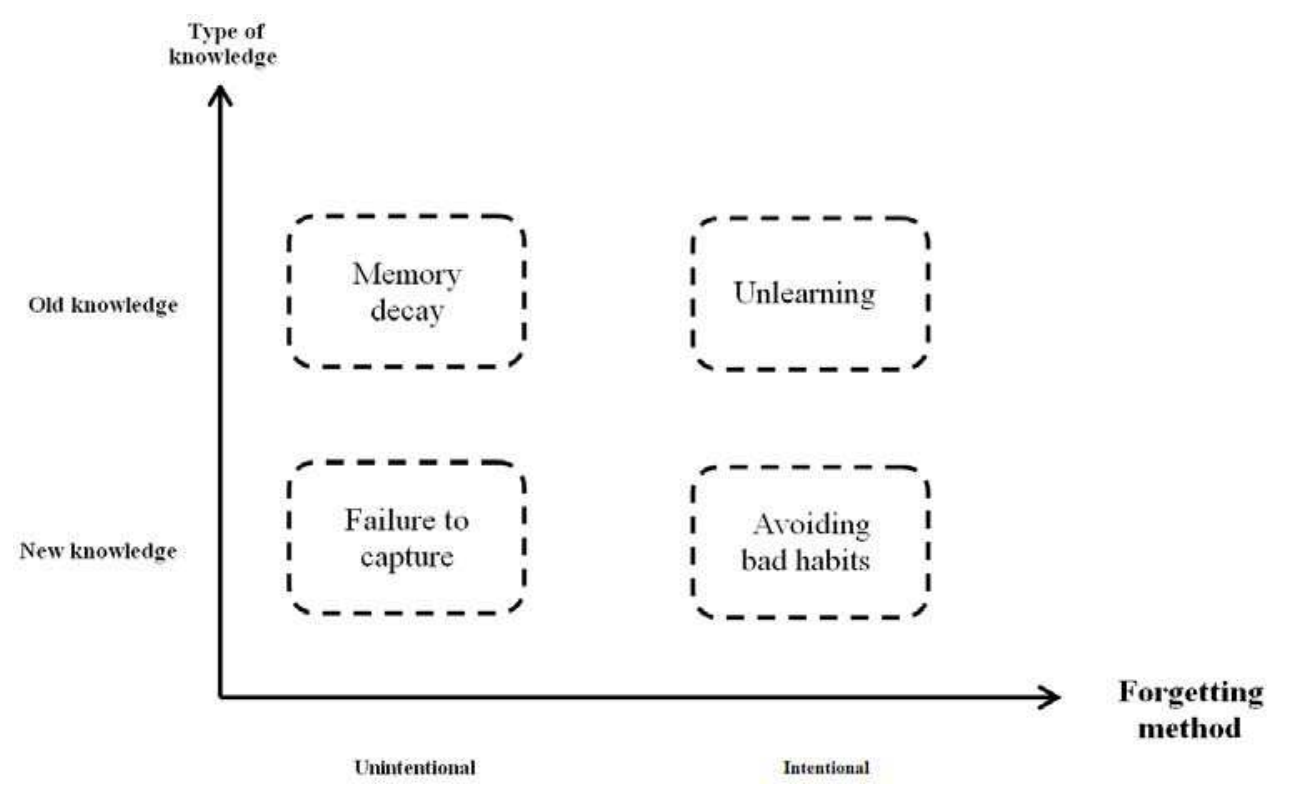

Fig. 1. Aspects of organizational forgetting

Failure to capture: refers to the situation in which the organization fails to keep the new knowledge and lose it due to lack of program.

Memory decay: refers to the situation in which the organization unintentionally and suddenly loses its access to the old knowledge.

Unlearning: refers to abandoned knowledge and information that may threaten success of the organization.

Avoiding bad habits: refers to the organization's ability to avoid habits, instructions, processes,

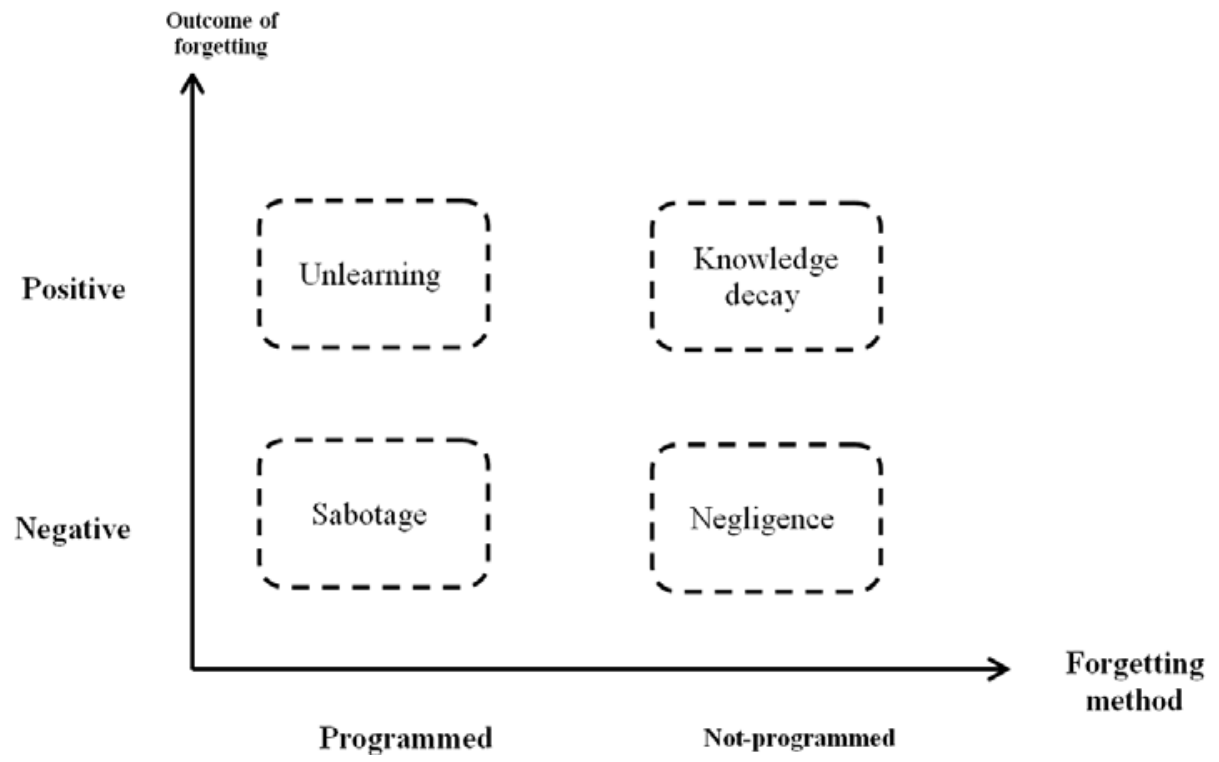

Fig. 2. Aspects of organizational forgetting forgetting messages (positive and negative). They argued that forgetting can result in positive and negative outcomes, which could be the case for both new and old knowledge. beliefs, and unacceptable values that threaten current activities of the organization (Wenbin et al., 2006).

Along with the outcomes of forgetting (positive and negative) Azmi (2008) highlighted forgetting method (intentional and unintentional). The intentional and unintentional aspects have been noted by Hedberg as wanted and unwanted aspects, respectively. An organization might forget knowledge in an intentional or unintentional manner and like new and current knowledge, they might result in positive and negative outcomes. 
Taking into account different types of forgetting and advantages of intentional organizational forgetting, only the two types of intentional forgetting and their relationship with the edge of chaos are in the scope of the study.

1.1. Edge of chaos and quantum learning. Quantum organization. Quantum organizations are featured with specific characteristics that make them differentiable from Newton's paradigm-based organizations. In general, degradable, vertical, mechanical, hierarchical, and segmental features are common in Newton (traditional) organization and multi-aspect, multi-directional, crossover, relational, and hybrid features are common in quantum organizations (Malloch and Porter-O'Grady, 2007).

Quantum organization is dynamic, adaptable, agile and borderless in which innovation and information flow freely. Apparently, one reason for these capabilities is abandoning traditional, hierarchical, and pyramidal structure of traditional organizations. These organizations are capable to maximize advantage of network structure - i.e., flexibility and pace. They are featured with multi-directional communications and multi-skill employees who work in an environment with high trust level. The managers reduce the need for intervention and leadership by clarifying the goals and intentions and emphasizing on creating common interests. Therefore, quantum organizations enjoy different communication processes to create common perspective and clarify purposes (Shelton and Darling, 2004).

Communication channels are the main elements of complicacy of the organizations, which is quite evident in quantum organization. By emphasizing on communications, these organizations try to facilitate communications in the organization through decentralizing, implementing autonomous structures, and utilizing vertical, horizontal, and oblique communications (Collins and Porras, 1994)

1.2. The edge of chaos. Edward Lorenz is a leading figure in introducing the theory of chaos and during the works to develop the theory, terms "theory of chaos" was replaced by more general term "theory of complexity". The theory deals with the mathematics of nonlinear dynamic behavior in natural systems, while the theory of complexity deals with the applications in complicated social systems (along with natural systems (Jackson, 2003). The theory of complexity focuses on chaos, lack of rule, and spontaneity. The theory accepts instability, change, and unpredictability and introduces effective solutions to manage these situations. The concept of the edge of chaos enters quantum learning field from the theory of complexity. It is the threshold between chaos and discipline where formation of new patterns is highly probable. A system that reaches the edge of chaos is more probable to demonstrate selforganization process.

1.3. Quantum learning. Quantum learning is a comprehensive model that encompasses learning theory and the elements of human resources and combines the processes of research and education (Brewer and Gross, 2003). In fact, quantum learning deals with adding joyfulness to teaching and learning along with discovery. This type of learning focuses on providing the materials while the learners enjoy opportunity to participate in learning process (DePorter et al., 1999), where all neural networks of the brain are engaged and organize the material in a customized, natural, and meaningful manner (Zohar, 1997).

Quantum is the science of possibilities and it is in the environment of possibilities that people and groups find a chance to grow and develop. Since quantum learning is intuition-based on thoughts and reflections, learning happens spontaneously in one nano-second through glazing through the eyes of wisdom and inner knowledge (i.e., intuition). Human being have been blessed with this learning ability since the beginning of history, however, this potential can be actualized by a reflective, discipline, and calm brain. The learning is prone to mistakes and the rate of which can be reduced through academic education and experiences (Johnson, 2002).

1.4. Principles of quantum learning. Johnson (2000) and Chrisley (1995) introduced three operational principles for quantum learning (Hosseini et al., 2014):

1. The brain: The general wisdom or a comprehensive energy that comprehends and amplifies the universe and real things. It strengthens our though system and creation of new version of life based on the moments (form one moment to another). Quantum leaning is the common knowledge of man and part of their brain, which is not employed.

2. Intuition (quantum thinking): one's ability to create experiences by feeling and sense. The source of energy (the brain) forms our experiences in life. Quantum thinking means learning while thinking as one can direct their feelings and deeds by learning about their thoughts and intuition.

The mental model provides opportunity to improve group thinking within the frame of four processes:

- Paradigm tear: discussions about new paradigm triggered by emergence of new and conflictual properties. 
- Paradigm recognition: the newly developed paradigm and the old one in power are juxtapozed to discuss differences of things; where the edge of chaos is formed.

- Paradigm reorganization: a mental process that is formed through cognitive perfection, rethinking about issues and accepting new viewpoints (created based on possibilities and new alternatives).

Self-transformation and awareness: profound change in thinking systems and self-awareness. A new perception about how people can overcome cognitive deadlock in chaotic situation and ponder the issues in group and discover new options.

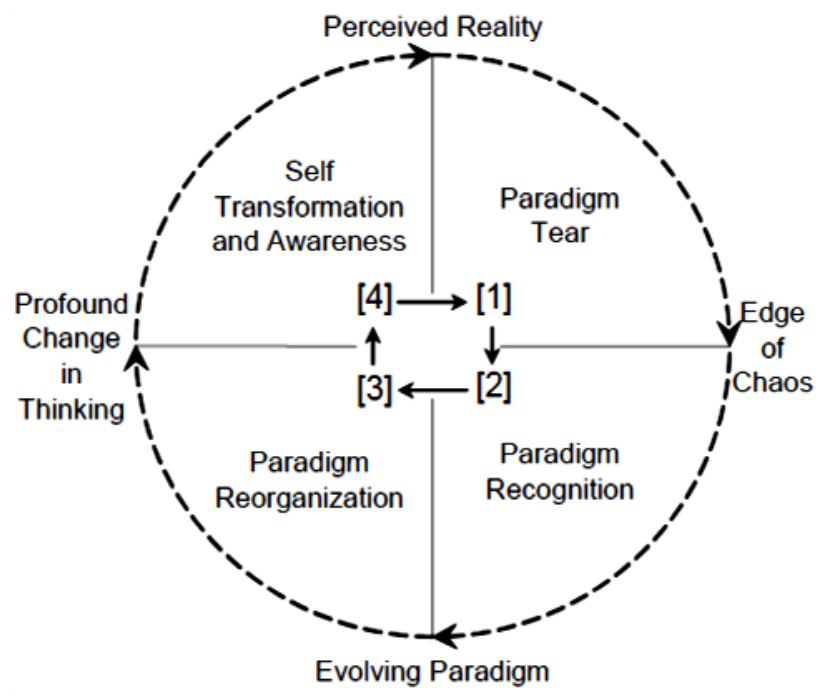

Fig. 3. Quantum thinking consciousness (self-awareness): ability to perceive life experiences through thinking, which is an attempt to learn, where one creates their experiences based on their thoughts.

These principles explain all feelings, emotions and behaviors - including madness of a murderer and happiness. The noted physician of the $20^{\text {th }}$ century, Albert Einstein believed that intuition is the foundation of man's true knowledge. They also help us to comprehend the man's immense learning capacity, thinking power rooted in quantum learning, and powers such as perspective, intuition, common feeling, analyzing, processing, and memory.

It is notable that man's thinking is rooted in routine or supernatural matters so that self-awareness is not identical with the nature but the former is the main reason for existence of the latter (Chrisley, 1995; Penrose, 1989; Boom, 1990). The thinking process is not a discrete process even when one' mind seems asleep (i.e., silence of the mind) so that it is more like a continuous routine process at different levels of the mind (unconscious mind) and leads to intuitive findings depending on one's level of accomplishment and intuition. This phenomenon (quantum jump by the brain) is called by the East mysticism as extension (Harman and Clark, 1994; Arons and Peppard, 1965; Fornaciari and Lund Dean, 2001; Wolf, 1981; Shelton, 1999; Kakaie, 2003).

The following diagram illustrates human's brain system in a meta-algorithmic system.

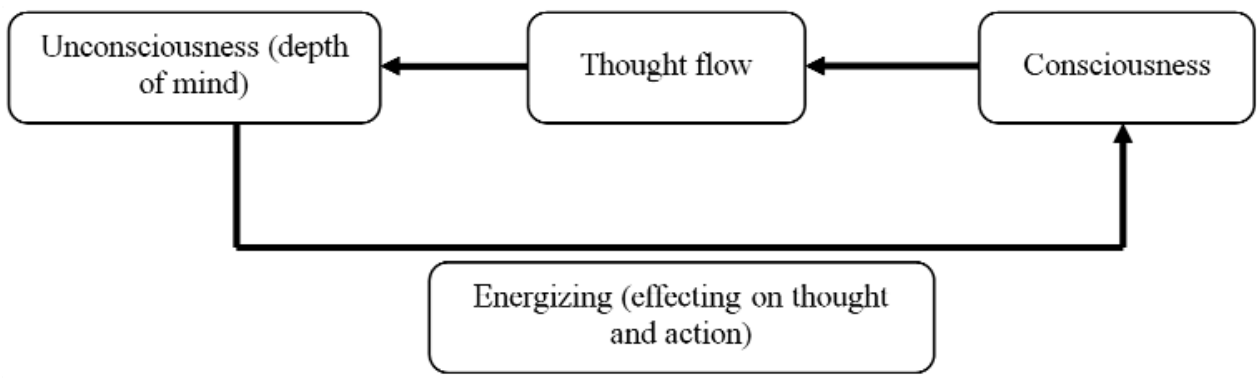

Fig. 3. The brain meta-algorithmic system

Quantum learning is not possible unless quantum jump is available. Continuous progress means that every quantum jump is learning opportunity and prepares the ground for the next jump. When learning is accelerated, the time interval between the jumps is reduced and we can take over our rivals.

\section{Methodology and conceptual model}

Based on the above, one may claim that, through quantum learning, the principles of quantum organization and the edge of chaos result in improvement of learning process and intentional forgetting in IT organizations. According to the concept of the edge of chaos, stable mechanical organizations are encountered with unchanging knowledge that is useless in some occasions. In such situation, the employees are interested in forgetting and abandoning the useless knowledge. Quantum organizations at the edge of chaos deal with updated, creative, and structured knowledge where the employees forget unnecessary knowledge. In over-unstable mood, the mechanical organization deals with unorganized knowledge, lack of knowledge, or irrelevant knowledge. The conceptual model of the study, therefore, is introduced as follows: 


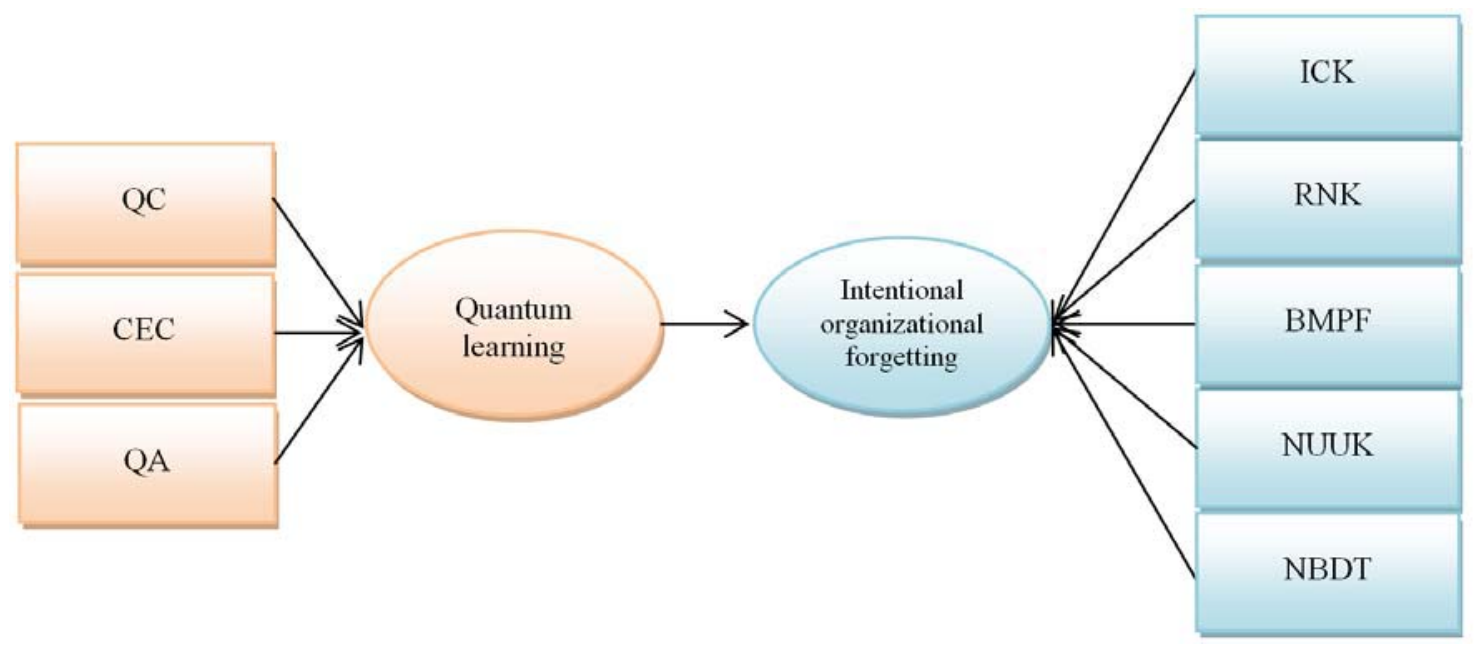

Fig. 4. Conceptual model

SEM is also called 'Covariance Structural Analysis', 'Causal Modeling' and 'LISREL Modeling'. Through SEM, general assumed structures or causal models with non-experimental data can be confirmed. SEM provides a coherent framework to assess the strength of relationships between all variables in a conceptual model. Theories are the bases of SEM and no explanation can be provided regarding the interrelationships of variables without considering the theoretical foundations. Structural equation is a technique of multivariate analysis that creates the possibility of simultaneous testing of a set of regression equations. In fact, SEM is a comprehensive statistical approach to test assumptions regarding the relationships between latent and observable variables.

Study population was comprised of 2700 individuals and based on Morgan's table, 338 participants were selected. Out of two series of questionnaires handed over to the participants and after removing unfilled questionnaire, 289 questionnaires formed the basis of data analyses.
Using Cronbach's alpha and KMO and Bartlett tests, the reliability and validity of both questionnaires were determined (Table 1).

Table 1. Cronbach's alpha coefficients to measure reliability of the questionnaires

\begin{tabular}{|l|c|}
\hline \multicolumn{1}{|c|}{ Index } & Cronbach's alpha \\
\hline Intentional organizational forgetting & 0.722 \\
\hline Quantum learning & 0.739 \\
\hline
\end{tabular}

Table 2. Bartlett's and KMO's coefficients to measure validity of the questionnaire

\begin{tabular}{|l|c|c|}
\hline \multicolumn{1}{|c|}{ Index } & $\begin{array}{c}\text { KMO \& Bartlett's } \\
\text { coefficient }\end{array}$ & Sig \\
\hline Intentional organizational forgetting & 0.819 & 0.001 \\
\hline Quantum learning & 0.740 & 0.001 \\
\hline
\end{tabular}

\section{Findings}

What we need to do is to prove that quantum learning can affect intentional organizational forgetting. To measure goodness of fit of the model, SEMs were employed (AMOS). The results of goodness of fit based on standard and non-standard coefficients are pictured in figure 4 and 5 .

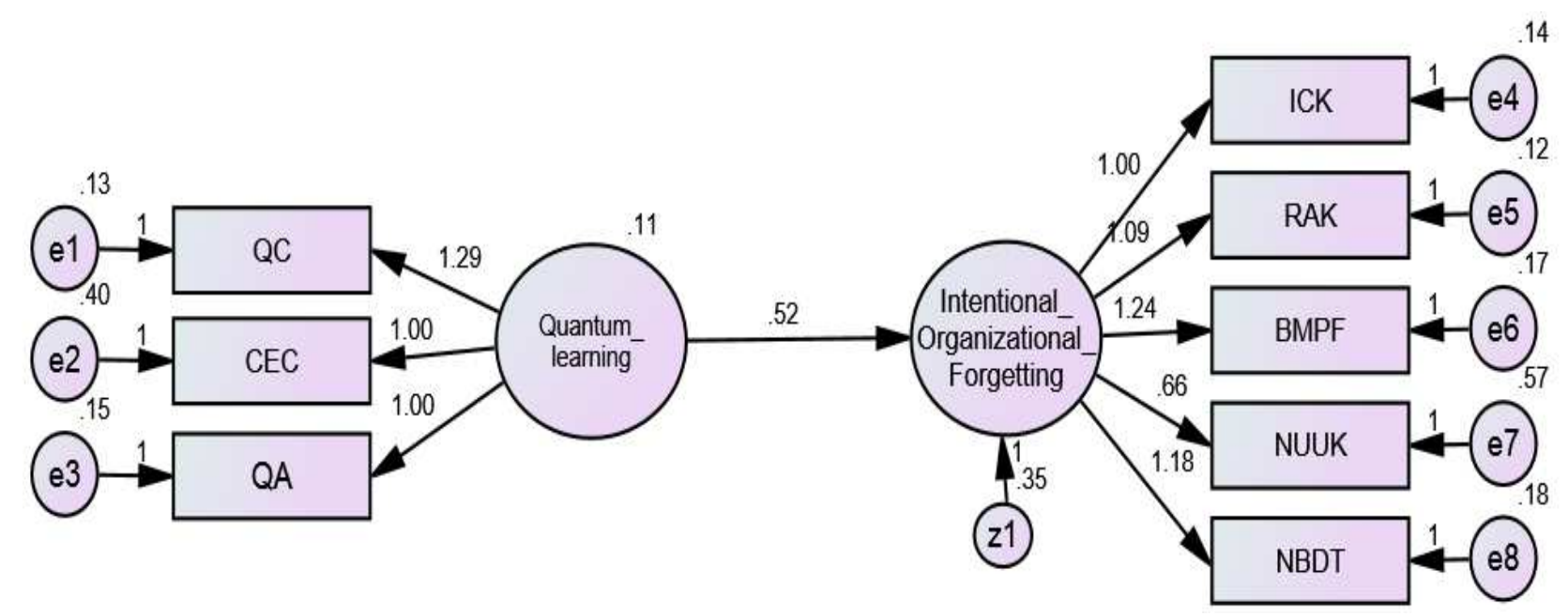

Fig. 5. Non-standard coefficients of the model 


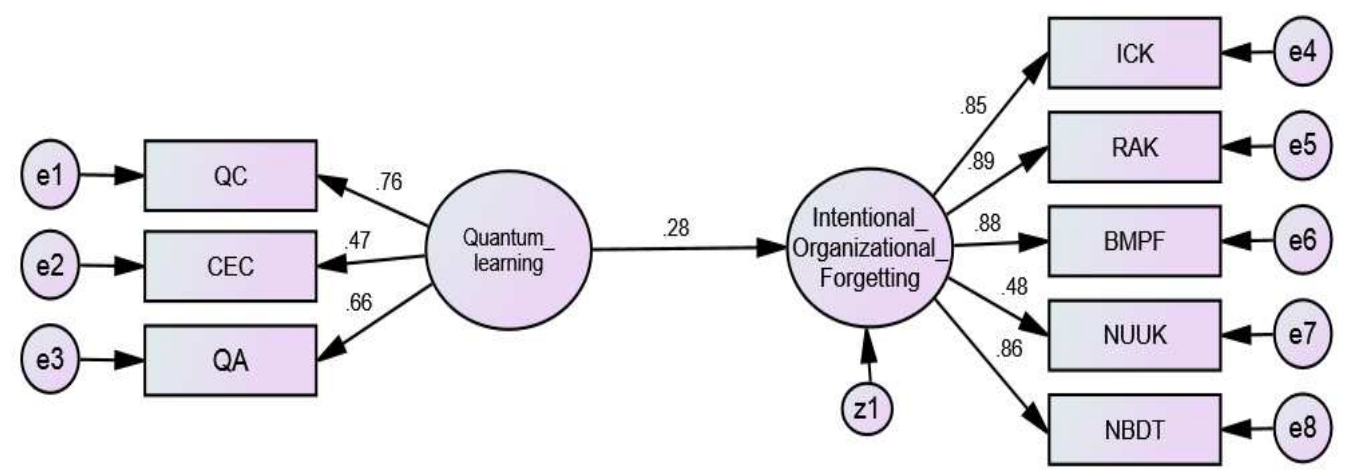

Fig. 6. Standard coefficients of the model

Table 3 lists the results as with significance of the path coefficients.

Table 3. Significant of path coefficients

\begin{tabular}{|l|c|l|c|c|c|c|}
\hline & & & Estimate & S.E. & C.R. & P \\
\hline Intentional_Organizational_Forgetting & $<---$ & Quantum_learning & .524 & .160 & 3.264 & .001 \\
\hline ICK & $<---$ & Intentional_Organizational_Forgetting & 1.000 & & & \\
\hline RAK & $<---$ & Intentional_Organizational_Forgetting & 1.092 & .063 & 17.330 & ${ }^{* * *}$ \\
\hline BMPF & $<---$ & Intentional_Organizational_Forgetting & 1.237 & .073 & 17.034 & ${ }^{* * *}$ \\
\hline NUUK & $<---$ & Intentional_Organizational_Forgetting & .664 & .090 & 7.348 & ${ }^{* * *}$ \\
\hline QA & $<---$ & Quantum_learning & 1.000 & & & \\
\hline CEC & $<---$ & Quantum_learning & 1.000 & .192 & 5.207 & ${ }^{* * *}$ \\
\hline QC & $<---$ & Quantum_learning & 1.292 & .240 & 5.372 & ${ }^{* * *}$ \\
\hline NBDT & $<---$ & Intentional_Organizational_Forgetting & & & & \\
\hline
\end{tabular}

As listed in the table above, all the paths RMSEA $=0.101>0.1$. Thereby, the model was are significant. On the other hand, surveys of modified based on suggestions by the software the indices of goodness of fit indicate that (Figure 7 and 8).

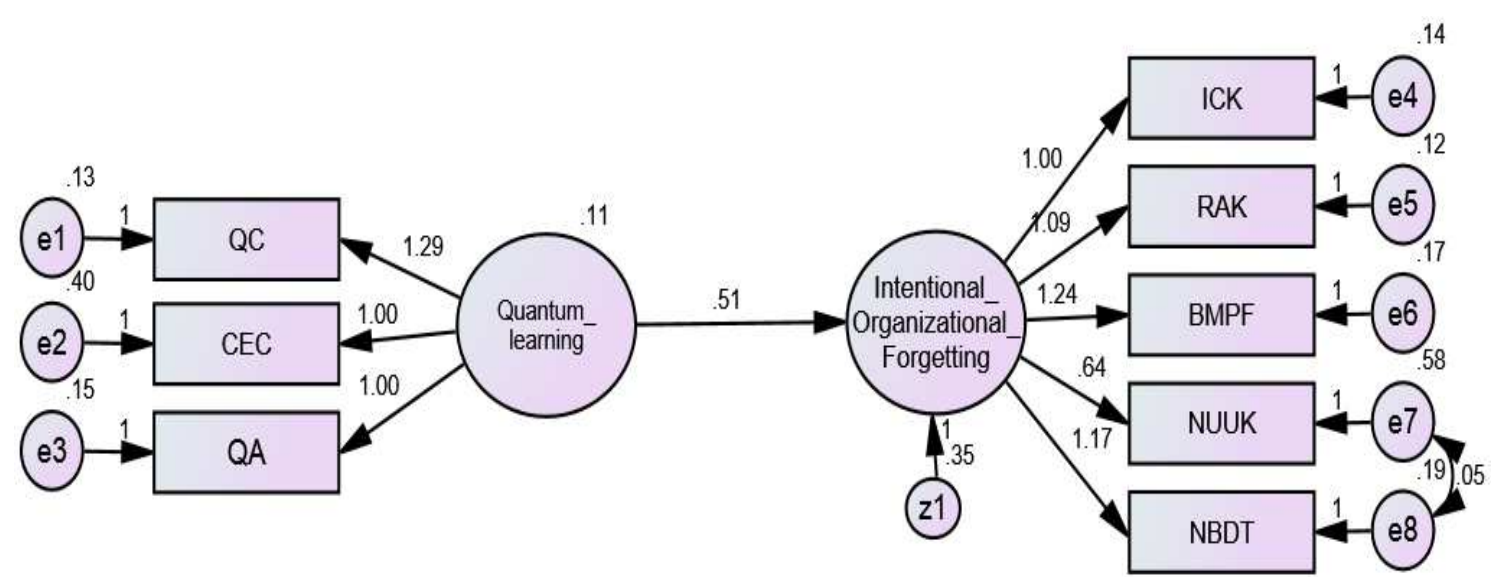

Fig. 7. Non-standard coefficient of the modified model

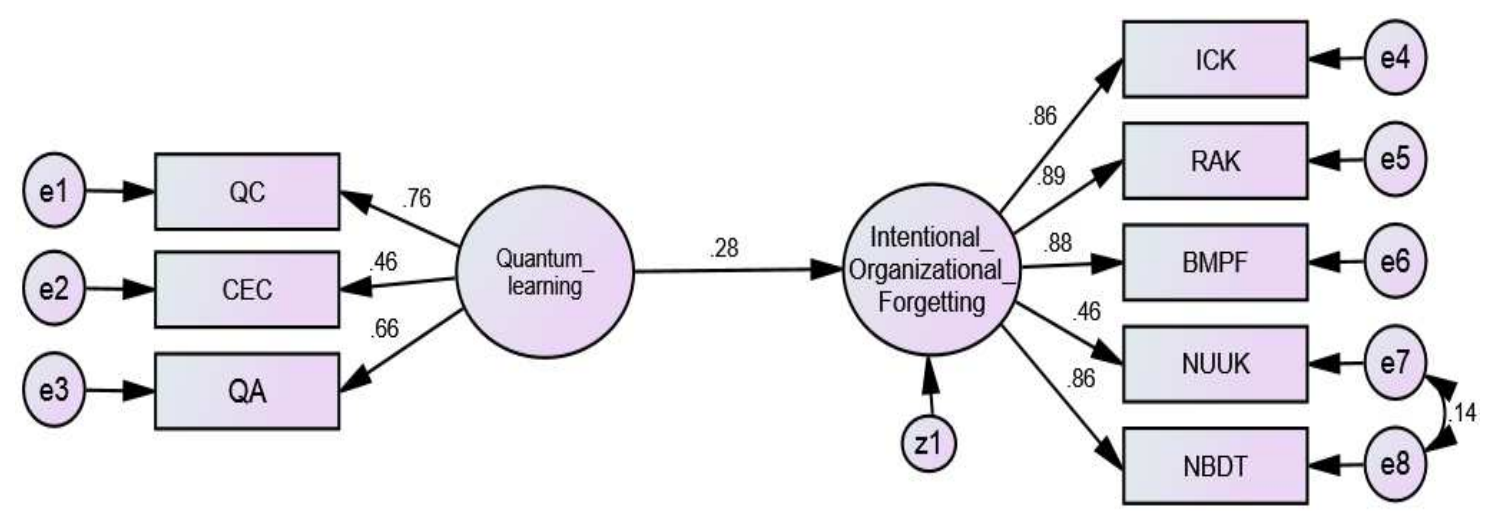

Fig. 8. Standard coefficients of the modified model 
Table 4 lists the results as with significance of the path coefficients of the modified model.

Table 4. Significance of path coefficients

\begin{tabular}{|c|c|c|c|c|c|c|}
\hline & & & Estimate & S.E. & C.R. & $\mathrm{P}$ \\
\hline Intentional_Organizational_Forgetting & $<--$ & Quantum_learning & .513 & .160 & 3.198 & .001 \\
\hline ICK & $<--$ & Intentional_Organizational_Forgetting & 1.000 & & & \\
\hline RAK & <--- & Intentional_Organizational_Forgetting & 1.090 & .063 & 17.424 & $* * *$ \\
\hline BMPF & $<--$ & Intentional_Organizational_Forgetting & 1.236 & .072 & 17.132 & *** \\
\hline NUUK & $<--$ & Intentional_Organizational_Forgetting & .638 & .091 & 6.984 & *** \\
\hline QA & $<--$ & Quantum_learning & 1.000 & & & \\
\hline CEC & $<--$ & Quantum_learning & .997 & .192 & 5.197 & $* * *$ \\
\hline QC & $<--$ & Quantum_learning & 1.290 & .241 & 5.348 & *** \\
\hline NBDT & $<---$ & Intentional_Organizational_Forgetting & & & & \\
\hline e7 & $\langle->$ & e8 & .046 & .026 & 2.756 & $* \star * \star$ \\
\hline
\end{tabular}

As listed in the table above, all the estimated path coefficients are significant. Goodness of fit indices are listed in Table 5.

Table 5. Goodness of fit indices of the modified model.

\begin{tabular}{|l|l|l|l|l|l|l|l|}
\hline $\begin{array}{l}\text { Goodness of } \\
\text { fit index }\end{array}$ & $\chi^{2} / d f$ & RMSEA & GFI & IFI & TLI & NFI & CFI \\
\hline $\begin{array}{l}\text { Acceptable } \\
\text { range }\end{array}$ & $<5$ & $<0.1$ & $>0.9$ & $>0.9$ & $>0.9$ & $>0.9$ & $>0.9$ \\
\hline Result & 2.594 & 0.076 & 0.929 & 0.957 & 0.936 & 0.928 & 0.959 \\
\hline
\end{tabular}

Comparing goodness of fit indices and the acceptable ranges, it is clear that all the indices are acceptable, which means the final model is acceptable. Therefore, the main hypotheses regarding effectiveness of quantum learning on intentional organizational forgetting is supported. This effect is positive and is equal with 0.51 and 0.28 in non-standard and standard moods, respectively.

\section{Discussion and conclusion}

The age of organized organizations is marching toward the era where the organization needs to reorganize them as a routine task to deal with the demands imposed by the environment. As complicated adaptable systems, organization stay in an unstable balance condition at the edge of chaos. In this case, strategy leaders prepare the ground for the system to adapt, survive meaningfully, react to the environment, develop, and positively influence the environment. Implementing such a critical and complicated role entails managers capable to fulfill functions such as cognition-direction, communication, adaptation (adjusting behavior of oneself and the system relative to the environment), and management of the interactive environment in a cooperative atmosphere. In addition, being equipped with strategic thoughts and capabilities in the field of strategic methodology and adopting perfection approach toward the strategy are required in practice. According to the theory of chaos, the universe is a nonlinear, complicated, and unpredictable systems. The theory refers to systems featured with intrinsic and hidden order, which are chaotic at the surface and represent chaotic, nonlinear, complicated, and unpredictable behaviors. The theory argues that there is a deep order in all chaotic systems. Nonlinear and complicated nature of chaotic systems problematizes developing a model of the systems. Instead of rejecting and devaluating experiencing and testing, the manager needs to let the employees to experience and learn from their experiences. Because of its complicated nature, experiencing and acquiring knowledge can be a valuable information source for the organizations, which also improve cognitive capabilities. Chaotic systems make it impossible to determine a preset plot or a mechanized plan. Information, awareness, experience, and trial can lead to knowledge in these systems. For instance, some of the cancers types cannot be diagnosed based on cell morphology and a wide information base and experiences are used to diagnose a cancer. Knowing that quantum learning and emphasis on the edge of chaos theory positively influence organizational forgetting, this learning method can be considered as a valuable input for the organization. The final goal of quantum learning is to facilitate and accelerate implementation of culture based on creativity and respecting the ethics. This learning method is rooted in mystical and traditional trainings and tries to combine learning and modern age science. As with learning, quantum jump of the unconscious mind is highly emphasized. Thereby, individuals' learning capability and scope of thoughts are beyond one's imagination and dynamism and stability of the organization are sought for through this. 


\section{References}

1. Arons, A., Peppard, A. (1995). Einstein's proposal of the photon concept - a translation of the annalen der physic paper of 1905, American Journal of Physics, 33, $368 \mathrm{p}$.

2. Aydin, E. \& Sahin Gormus, A. (2015). Does organizational forgetting matter? Organizational survival for life coaching companies, The Learning Organization, 22 (3), pp. 150-162.

3. Azmi, F. (2008). Mapping the learn-unlearn-relearn model: Imperatives for strategic management, European Business Review, 20 (3), pp. 240-259.

4. Boom, D. (1990). A new theory of the relationship of mind and matter, Philosophical Psychology, 3 (2), pp. 271-286.

5. Brewer, C.A., Gross, L.J. (2003). Training Ecologists to Think with Uncertainty in mind, Ecology, 84 (6), pp. 1412-1414.

6. Chrisley, R.L. (1995). Quantum Learning. School of cognitive \& computing science, University of Sussex, United Kingdom.

7. Collins, J. \& Porras, J. (1994). Built to last: Successful Habits of Visionary \& Companies. San Francisco, CA: Harper-Collins.

8. DeHolan, P., Philips, N. \& Lowrence, T. (2004). Managing Organizational Forgetting, MIT Sloan Management Review, 45 (3), pp. 45-51.

9. DePorter, B., Reardon, M., Singer-Nourie, S. (1999). Quantum Teaching Orchestrating Student Success. Massachusetts: A Viacom Company.

10. Fernandez, V. \& Suñé, A. (2009). Organizational Forgetting in Higher Education. 3rd International Conference on Industrial Engineering and Industrial Management, pp. 619-626, Barcelona.

11. Fornaciari, C.J., Lund D.K. (2001). Making the quantum leap: Lessons from physics on studying spirituality and religion in organizations, Journal of Organizational Change Management, 14 (4), 335 p.

12. Harman, W., Clark, J. (1994). New methaphysical framework of modern science. Sausalito, CA: Institute of Noetic Sciences.

13. Hedberg, B. (1981). How organizations learn and unlearn, Handbook of Organizational Design, Oxford, UK: Oxford University Press, 1, pp. 3-27.

14. Hosseini, S.F., Asghar, M., Azam, S. (2014). Quantum learning: a new paradigm toward organisational fragility elimination, International Journal of Learning and Intellectual Capital (IJLIC), 11 (2).

15. Jackson, M.C. (2003). Systems Thinking: Creative Holism for Managers. John Wiley and Sons Ltd, pp. 113-135.

16. Kakaie, Q. (2003). Pantheism narrated Ibn Arab and Meister Eckhart. Tehran: Hermes Press with collaboration with the International Center for Dialogue Among Civilizations.

17. Malloch, K. \& Porter-O'Grady, T. (2007). The Quantum Leader: Applications for the new world. $2^{\text {nd }}$ ed. Boston, MA: Jones and Bartlett.

18. Ozkan, S. \& Koseler, R. (2009). Multi-dimensional students' evaluation of e-learning systems in the higher education context: An empirical investigation, Computers \& Education, 53, pp. 1285-1296.

19. Penrose, R. (1989). The emperor new mind. Oxford: Oxford University Press.

20. Schaff, J.D. (2002). Quantum learning: Leadership for learning organizations Futurics, Academic Research Library, 26 (3/4), $89 \mathrm{p}$.

21. Shelton, C. \& Darling, J.R. (2004). From chaos to order: Exploring new frontiers conflict management, Organization Development Journal, 22 (3), pp. 22-41.

22. Shelton, C. (1999). Quantum Leaps: 7 Skills for Workplace recreation. Boston: Butterworth-Heinemann.

23. Wenbin, N., Wei, G. \& Zhang, L. (2006). The model of organizational forgetting and the research of management strategy, Journal of Harbin Institute of Technology, 8 (3), pp. 73-77.

24. Wolf, R.K. (1981). Taking the quantum leap. San Francisco, CA: Harper \& Row Publishers.

25. Zohar, D. (1997). Rewriting the corporate brain. San Francisco: Berrett-Kohler. 